\title{
CHIEF INFORMATION OFFICERS: An EMPIRICAL STUDY OF COMPETENCE, ORGANISATIONAL POSITIONING AND IMPLICATIONS FOR PERFORMANCE
}

Jason F Cohen and Claire M Dennis

School of Economic and Business Sciences, University of the Witwatersrand

Accepted February 2010

\begin{abstract}
The role and contribution of the firm's Chief Information Officer has been the subject of much debate and uncertainty. Yet, too few empirical studies have examined the implications of the $\mathrm{ClO}$ role. This study examined the effects of $\mathrm{ClO}$ demography, $\mathrm{ClO}$ competencies as well as $\mathrm{CIO}$ organisational positioning on the contribution of information systems (IS\&T) to business performance. Data were collected from 111 South African companies and results revealed that $\mathrm{ClO}$ business, interpersonal/political and technology management competence have significant direct effects on the dependent variable. The effect of $\mathrm{ClO}$ organisational position, including structural power and political relationship, was found to be mediated by $\mathrm{ClO}$ competence. $\mathrm{ClO}$ work experience also impacted the contribution of IS\&T. Results have important implications for our understanding of the competencies and organisational positioning required of executives charged with the responsibility for information systems and technology management.
\end{abstract}

Keywords: Information systems management, chief information officer, competence, top management, upper echelons, performance

JEL M14

1

\section{Introduction}

Improved contribution of information systems (IS) and their underlying technologies (IT) to organisational performance is a key business objective. However, there are observed differences across firms in their abilities to extract value from their information systems and technology (IS\&T) investments, to control IS\&T costs, and effect business strategies through IS\&T implementation (Chatterjee, Richardson \& Zmud, 2001). To ensure that IS\&T makes maximum contribution towards the achievement of organisational goals, organisations have placed increasing emphasis on their IS\&T management practices. There is a particular need for a senior executive to take responsibility for the management of corporate information resources (Stephens, Ledbetter, Mitra \& Ford, 1992), to ensure the alignment of business and IS\&T (Chatterjee et al., 2001), and to be a "change agent" - increasing the organisation's ability to adapt to the external environment (Stephens \& Loughman, 1994). This senior executive is commonly referred to as the organisation's Chief Information Officer (CIO).

The CIO role marks a shift in historic approaches to IS\&T management, which often viewed the IS\&T manager as a functional line manager and technical expert (Applegate \& Elam, 1992). However, as IS\&T evolved to play a more strategic role, an evolution in the CIO role occurred. This evolution has been described as a movement from 'backroom to 
boardroom $^{1}$, where the CIO is elevated to the level of other executives such as marketing, finance, manufacturing, human resources, and operations (Romanczuk \& Pemberton, 1997).

However, the CIO position is not a simple one. The CIO must deal with strategic business issues alongside the challenges of technology management (Watson, Kelly, Galliers \& Brancheau, 1997). The CIO needs to plan strategically for IS\&T and align IS priorities with the strategic information needs of the organisation whilst also ensuring continuity of IS\&T services, infrastructure and application provision. CIOs operate in an environment where past practices have little bearing on future success (Gartner, 2007), and where organisational context still causes wide variations in management role, reporting levels, and nature of interactions with other executives (Grover, Jeong, Kettinger \& Lee, 1993).

Despite some reports on the positive impacts of CIOs (Chatterjee et al., 2001) and some optimistic surveys on the state of CIOs (CIO.com, 2009), the popular international press, consulting reports, and the academic literature have questioned the contribution of the CIO to business success and point to CIOs as being at the centre of a crisis of confidence (Earl \& Feeny, 1995). In the UK, CIOs are still scarce amongst senior management teams, and are burdened by disappointment around IT contribution (Delloitte UK Survey, 2008). Seen as failing to deliver on IT's expectations, some have described CIOs as an 'endangered species' (Perlman, 2007) facing the 'dumbing down' of their role (Overby, 2003).

These concerns call for increased attention to researching IS\&T leadership and the role of the CIO (Karahanna \& Watson, 2006). Yet descriptive research into the CIO role has not consistently been undertaken (Gottschalk \& Taylor, 2000; Grover et al., 1993); empirical work is only just emerging into the effects of CIO background and demography ( $\mathrm{Li}$, Tan, Teo \& Tan, 2006; Sobol \& Klein, 2009); and despite some efforts, the determinants and consequences of CIO hierarchical level and engagement with the CEO and top management team are not fully understood (Feeny, Edwards \& Simpson, 1992; Banker, Hu \& Pavlou, 2004; Karimi, Gupta \& Somers, 1996; Armstrong \&
Sambamurthy, 1999; Enns, Huff \& Higgins, 2003; Johnson \& Lederer, 2005; Preston, Karahanna \& Rowe, 2006; Ranganathan \& Jha, 2008). The concept of CIO role effectiveness has only recently gained attention and scholars are just beginning to ask questions about the capabilities and characteristics of CIOs that result in improved role effectiveness and consequent company performance (Ravarini, Moro, Tagliavini \& Guimaraes, 2001; Pigni, Ravarini, Tagliavini, Moro \& Guimaraes, 2002; Smaltz, Sambamurthy \& Agarwal, 2006; Lane \& Koronios, 2007; Chen \& Preston, 2008; Wu, Chen \& Sambamurthy, 2008).

Thus there still remains a dearth of empirical evidence of causal relationships between CIO characteristics and various outcome and performance measures (Wu et al., 2008). Prior studies referred to above have often presented inconclusive and inconsistent findings on the impacts of CIO competence (Pigni et al., 2002; Smaltz et al., 2006; Wu et al., 2008). Prior research has also done little to explore the combined and relative effects of CIO demography, competence and the CIO's organisational position on IS\&T performance. Past research, in the South African context, has been limited to descriptive studies focused on the changing CIO role (Evans, 2006) and on CIO management challenges (Johnston, Muganda \& Theys, 2007). Consequently, we still lack answers to fundamental questions about the $\mathrm{CIO}$ role. What contributions can the CIO make to improving IS\&T performance? What are the appropriate characteristics, competencies and skills required of CIOs? And what organisational position is required to facilitate $\mathrm{CIO}$ role effectiveness so that improvements in IS\&T outcomes can be observed?

As information systems and their underlying technologies become a more strategic resource for organisations in developing economies such as South Africa, we need answers to these questions The purpose of this study is therefore to improve our understanding of the competencies and organisational positioning required of executives charged with responsibility of IS\&T management by empirically examining the influence of CIO competence, demography and organisational positioning on the contribution of IS\&T to business performance. 
The next section of this paper introduces the research model and its theoretical underpinnings. This is followed by hypothesis development. The research method is outlined and then empirical results are presented. Findings are discussed, which include implications for research and practice.

\section{2}

\section{Theoretical background and research model}

Improving the business value of IS\&T lies at the heart of IS management research and is one of the key concerns of CIOs in practice. Organisations will typically look toward IS\&T to achieve operational effectiveness and strategic positioning (Rivard, Raymond \& Verreault, 2006). However, IS\&T is all too often associated with high failure rates and disappointing returns on investment and it falls to the CIO to improve IS\&T contribution by making important strategic decisions about the deployment of IS\&T resources. To reflect these ultimate concerns of the CIO, the dependent variable of this study is the contribution of IS\&T to business performance. This IS\&T outcome measure is defined as the contribution made by IS\&T products and services implemented within the organisation to operational effectiveness (through improvements to organisational productivity and cost reduction) and to strategic positioning (through impacts on profitability, product/service differentiation, and customer satisfaction).

The research model (Figure 1) depicts hypothesised effects of CIO background, capabilities and organisational positioning on the dependent variable. The research model is underpinned by the upper echelons perspective (Hambrick \& Mason, 1984) and the power and politics perspective on organisations (Pfeffer, 1992). Together these theories support the view that CIO leadership is at the centre of cognitive, political and social processes in organisations (Karahanna \& Watson, 2006) and that CIO characteristics can therefore affect IS\&T outcomes.

\subsection{CIO competence and demography}

The upper echelons perspective of Hambrick and Mason (1984) argues that organisations are reflections of the backgrounds, cognitions and beliefs of its top managers, and therefore any attempt to understand organisational outcomes must include consideration of top executives. Proponents of the upper echelons perspective cite the behavioural view of decision making as the underlying mechanism for how managerial backgrounds influence organisational outcomes (Finkelstein and Hambrick, 1990). This is because decision makers act on the basis of personalised interpretations of the strategic situations they face; they bring their experiences, values, preferences and knowledge to each decision situation (Hambrick \& Mason, 1984). Therefore, managers' characteristics are considered determinants of their strategic choices and thus organisational performance. This perspective is considered particularly pertinent to executives such as the CIO who has complex managerial roles that require the integration of various sources of information from across the organisation, and where the importance assigned to information and consequent decisions on priorities would be heavily subject to interpretation and cognitive limitations (Finkelstein \& Hambrick, 1990).

Most upper echelons research captures such effects through the consideration of executive demographics such as age, experience and education (e.g. Wiersema \& Bantel, 1992). However, more recent upper echelons work has argued that managerial cognitions and values cannot be fully captured by demographics alone (e.g. Yun, 2007), and other managerial characteristics should be explored for their influence on leadership and organisational outcomes (Krishnan \& Park, 1998). Figure 1 incorporates both $\mathrm{CIO}$ demography and the concept of managerial competence, which captures the richer upper echelon attributes of knowledge, skills and ability (Hoffman, 1999).

\subsection{CIO organisational positioning}

Figure 1 also illustrates the effects of CIO organisational positioning. Organisational position of the CIO is most often considered in terms of structural power i.e. the rank of the CIO reflected by reporting level (Banker et al., 2004; Karimi et al., 1996), and in terms of political 
relationships reflected by the frequency of the CIO's interaction with the chief executive of the organisation, and the CIO's active involvement in the organisation's top management team (TMT) (Armstrong \& Sambamurthy, 1999; Smaltz et al., 2006; Preston, Chen \& Leidner, 2008).

Figure 1:

Research model

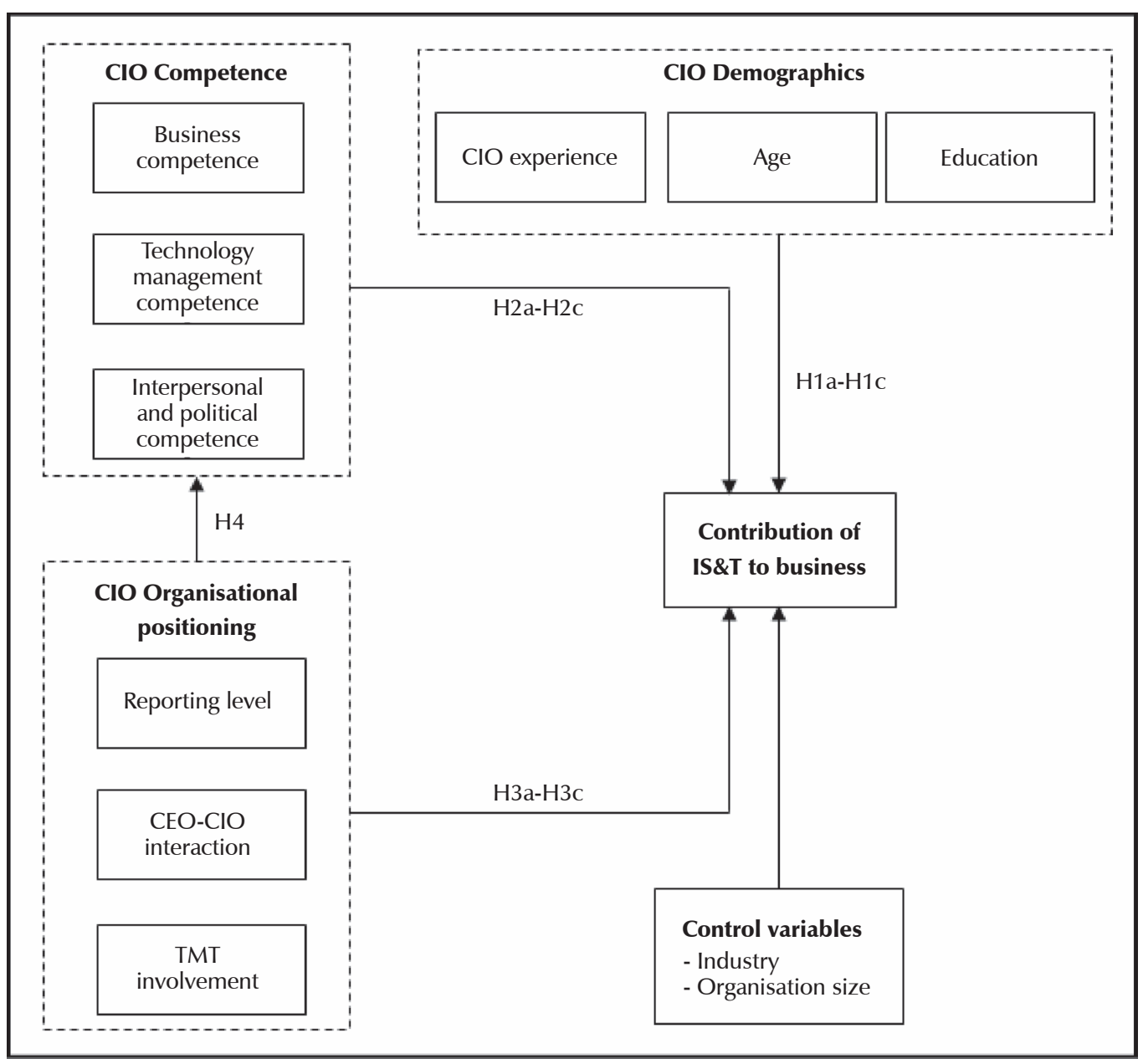

The proposition that the CIO's organisational position will affect IS\&T outcomes is supported by the power and politics perspective on organisations (see Eisenhardt \& Zbaracki, 1992 for a review). The power and politics perspective of organisations describes power and influence as primary mechanisms through which people get things done (Pfeffer, 1992). One source of power is structural or position power, which is usually exemplified by hierarchical position (Astley \& Sachdeva, 1984). Power stems from authority and is inherent in the official position of managers and executives. Structural power provides the CIO with a legitimate base for influencing organisational action (Preston et al., 2008). However, since IS\&T implementations are organisational in scope and affect processes and structures across organisations, it has also been suggested that CIOs need to gain commitment of fellow TMT members for IS\&T induced changes (Enns, Huff \& Golden, 2001). Therefore, another important source of power is 
political influence. This type of political influence is typically characterised by alliance behaviour and development of stable coalitions with other key executives (Eisenhardt \& Bourgeois, 1988). The CIO establishes these political relationships through interaction and participation with the CEO and TMT, which provides the CIO with avenues for conflict resolution, cooptation and coalition formation (Eisenhardt \& Zbaracki, 1992) that can increase CIO power (Preston et al., 2008). Political relationship provides the $\mathrm{CIO}$ with the means to influence organisational action and the behaviour of other organisational members, to overcome resistance (Pfeffer, 1992), and become part of the 'dominant coalition' (Thompson, 1967).

Drawing on the above, hypotheses linking CIO demography, CIO competence and CIO organisational positioning to IS\&T business contribution can now be developed.

\section{3}

\section{Variables and hypotheses}

\subsection{CIO demography}

Following both Li et al. (2006) and Sobol and Klein (2009) CIO work experience along with age and level of education are included in the research model as 'observable' upper echelons characteristics (Hambrick \& Mason, 1984) with the potential to influence strategic choices and consequent performance

CIOs work at the technology/business interface (Karahanna \& Watson, 2006) and much discussion has taken place in both the academic and practitioner literature as to whether the $\mathrm{CIO}$ position should be occupied by an individual with a primary background in the functional areas of business versus an IS\&T specific background. Grover et al. (1993) show a very high average number of years of IS\&T specific work experience (24 years) in their sample of CIOs, while Johnson and Lederer (2005) report a lower average of 15 years. Long tenure within the IS\&T profession can restrict the breadth of a CIO's knowledge base and limit his/her perspective, while diverse functional experience could broaden perspectives and ensure that a range of alternatives and consequences is explored (Rajagopalan \& Datta, 1996). Yet, while Applegate and Elam (1992) conclude that 'individuals selected for senior IS executive positions will be increasingly required to have actual management experience outside the IS function' (page 476), Feeny et al. (1992) and more recently Sobol and Klein (2009) find that CIOs with technology backgrounds are associated with improved performance. A technology oriented background for the CIO may thus facilitate better decisions on IS\&T spending and resource allocation (Sobol \& Klein, 2009). The following hypothesis is posed:

\section{Hypothesis 1a: The greater the IS\&T work experience of the $\mathrm{CIO}$, the greater will be the contribution of IS\&T to business performance}

Roughly 70 per cent of the CIOs sampled in Li et al. (2006) were below the age of 45 . They argued that older CIOs are likely to be less technically knowledgeable, more risk averse and have greater difficulty grasping emerging challenges in IS\&T - all of which would have negative implications for the innovate use of IT. Although their field study of 89 CIOs led to the rejection of this hypothesis, age is as an important demographic variable argued by upper echelons theorists (Hambrick \& Mason, 1984) and it needs to be more fully determined whether it has implications for how the CIO manages IS\&T. Borrowing from the arguments put forward by Li et al (2006) it is hypothesised that:

\section{Hypothesis 1b: The greater the age of the CIO, the poorer will be the contribution of IS\&T to business performance}

Higher education was identified as a particularly desirable characteristic for CIOs by Gottschalk and Taylor (2000) with 34 per cent of the CIOs in their Norwegian sample having Masters Degrees. Other recent studies report from 22 per cent up to 43 per cent of CIOs as having postgraduate qualifications (Karimi et al., 1996; Johnson \& Lederer, 2005; Li et al., 2006). A higher level of formal education has the potential to influence how the $\mathrm{CIO}$ is perceived 
by other executives and how they will relate to the CIO (Karimi et al., 1996). From an upper echelons perspective, more educated CIOs may also have greater ability to absorb new ideas, tackle complex cognitive problems and thus be more innovative in the use of IS (Li et al., 2006). It is therefore hypothesised that:

\section{Hypothesis 1c: The higher the education level of the CIO, the greater will be the contribution of IS\&T to business performance}

\subsection{CIO competence}

As indicated above, this study incorporated the concept of managerial competence to capture the richer upper echelons attributes of knowledge, skills and ability (Hoffman, 1999). When corresponding to the requirements of a task, competencies enable individuals to produce effective performance (Hoffman 1999; McKenna, 2004). Improved IS\&T outcomes are thus likely to result when the CIO's specific competencies are aligned to the demands of their role (Romanczuk \& Pemberton, 1997). Three primary competencies for the CIO have been suggested by the IS literature (Bassellier \& Benbasat, 2004; Dawson \& Watson, 2005). These are: (a) business competence, which is reflected in CIOs knowledge and understanding of the internal and external business domain (Armstrong \& Sambamurthy, 1999; Bassellier \& Benbasat, 2004), (b) technology management competence, which is reflected in CIO's knowledge and understanding of technology and how it can be used to address business needs (Armstrong \& Sambamurthy, 1999), and (c) interpersonal and political competence, which is reflected in the ability to plan, organise, lead and interact with customers, peers, business partners and employees (Lee, Trauth \& Farwell, 1995). These correspond to the need for a CIO to know what (business knowledge), know how (technology management knowledge), and know how to be (interpersonal and political skill) (Tagliavini, Moro, Ravarini \& Guimaraes, 2003; Lane \& Koronios, 2007). These three competencies ensure a balanced CIO i.e. one that does not focus exclusively on technical issues or become socially isolated and unable to exert influence on top management peers (Enns et al., 2003).

Business competence includes understanding and knowledge of the organisation's industry, competitors, strategies, processes and products (Armstrong \& Sambamurthy, 1999; Bassellier \& Benbasat, 2004). The information systems literature maintains that strong business domain knowledge of IS executives is needed tor strategically align IS and business (Reich \& Benbasat, 2000; Dawson \& Watson, 2005), for successful technology assimilation (Armstrong \& Sambamurthy, 1999), partnership and engagement with the business (Bassellier \& Benbasat, 2004; Enns, 2005), recognising appropriate IS opportunities (Lee \& Pai, 2003), and translating advances in IS\&T into understandable and relevant business benefits (Earl \& Feeny, 1995). Increased business knowledge of the CIO supports the 'knowledge overlaps' needed for the CIO to apply IS\&T in support of the operational and strategic objectives of the organisation (Boynton et al., 1994). It is thus hypothesised that:

\section{Hypothesis 2a: The greater the business competence of the $\mathrm{CIO}$, the greater will be the contribution of IS\&T to business performance}

Although IS professionals generally start with a primarily technical focus, they move towards a technology management focus as they become charged with responsibility for ensuring that technology meets the needs of business (Lee, Yen, Havelka \& Koh, 2001). This technology management, rather than technical knowledge becomes an important career anchor for the senior IS professional (Armstrong \& Sambamurthy, 1999; Lofgren, 2003) and is highly emphasised in practice (Roepke, Agarwal \& Ferratt, 2000). Technology management knowledge includes an understanding of how to utilise IT to address business needs; identify emerging IT for supporting the organisation's strategies and processes; and guide the organisation's decisions related to IS\&T investment (Armstrong \& Sambamurthy, 1999). It is expected that CIOs with greater technology 
management knowledge will spend more time scanning the external IT environment, looking for technological advances, and learning about best practices in IS\&T use, development and management. It is therefore hypothesised that:

\section{Hypothesis 2b: The greater the technology management competence of the $\mathrm{CIO}$, the greater will be the contribution of IS\&T to business performance}

Interpersonal, political and organisational skills are considered another core competence for the CIO (Earl \& Feeny, 1995; Enns et al., 2003; Bassellier \& Benbasat, 2004). Interpersonal skills for a CIO would include the ability to work in a collaborative environment and manage interactions with business partners and users; the ability to organise and lead IS projects; and the ability to be a proactive agent for organisational change (Bassellier \& Benbasat, 2004; Lee et al., 1995). With appropriate interpersonal skills, CIOs will be more effective in adopting appropriate influence behaviours to gain support from others within the top management team for strategic IS initiatives (Enns et al., 2003). CIOs unable to build relationships may not be suited to strategic roles and are likely to be unable to deal with uncertainty and strategic decision making (Willcoxson \& Chatham, 2006). Evans (2006) argues that the highly political environment of today's South African organisations requires that CIOs are equipped to deal with challenges brought about by people rather than technology. Communication skills have been linked to the CIOs ability to bridge the worlds of IT and business, to persuade, inform and create meaning (Stephens \& Loughman, 1994). It is hypothesised that:

\section{Hypothesis 2c: The greater the interpersonal and political competence of the CIO, the greater will be the contribution of IS\&T to business performance}

\subsection{CIO organisational positioning}

In the case of the CIO, power structures (hierarchical position) and interactions with business executives enable the sharing of perspectives, development of understanding, and building of relationships (Armstrong \& Sambamurthy, 1999; Preston et al. 2006; 2008), which are seen as critical for achieving IS\&T performance (Ranganathan \& Kannabiran, 2004). CIOs with little power or political influence, CIOs who are considered low level managers, and CIOs viewed only as occasional technical consultants to the TMT will find it difficult to obtain managerial support of and input into IS\&T implementation processes (Stephens et al., 1992; Enns et al., 2001; Preston et al., 2008), and consequently will be ineffective in increasing IS\&T contribution to the organisation.

CIO hierarchical level is associated with authority and power to affect and influence organisational action (Tagliavini et al., 2003; Preston et al., 2008). CIOs only two levels below the CEO may be 'hindered in their positions' (Coghlan \& Hurley, 1996). Proximity between $\mathrm{CEO}$ and $\mathrm{CIO}$ can enhance the availability of resources and the support (for organisational changes) required for successful IS implementation (Ranganathan \& Kannabiran, 2004). In a multiple case study, Jain (1997) found CEO-CIO proximity to be among the 'administrative structures' relevant to the success of IS implementation efforts as such status helped ensure availability of resources and management support for IS. Higher ranked CIOs are also reported as being able to gain greater access to information from senior management and maintain an IS awareness among senior business management (Raghunathan \& Raghunathan, 1989). Higher ranking IS executives are likely to place more emphasis on strategic issues, look for ways in which IS can help support or shape the business, and focus on the effectiveness rather than efficiency of the IS function (Raghunathan \& Raghunathan, 1989). It follows that:

\section{Hypothesis 3a: The higher the reporting level of the CIO, the greater will be the contribution of IS\&T to business performance}

Frequency of communication enables the CEO/TMT and CIO to build consensus, reduce barriers, promote trust and ultimately facilitate convergence on the role of IS\&T 
and its expected contribution to the business (Johnson \& Lederer, 2005). Prior empirical studies confirm that the greater the interaction between the CEO and CIO, the greater the firm's use of IT (Jarvenpaa \& Ives, 1991) and the greater the firm's level of IT assimilation (Boynton et al., 1994). Interaction helps the $\mathrm{CEO}$ and CIO share information that may be strategically important to the organisation and can positively influence the CEO's view of IT (Jarvenpaa \& Ives, 1991). Communicating with the CEO, educating the CEO about IS, and learning from the CEO about the business helps ensure that CIOs better understand the CEO's goals for IS (Jones \& Arnett, 1994) and ensure that the CIO deploys IS\&T resources to support the business's critical activities (Johnson \& Lederer, 2005). It follows that:

\section{Hypothesis 3b: The higher the frequency of CEO-CIO interaction, the greater will be the contribution of IS\&T to business performance}

Unfortunately, CIOs are not typically active members of the corporate top management team (Jones, Taylor \& Spencer, 1995; Delloitte UK Survey, 2008). Yet, Earl and Feeny (1995) describe how TMT membership allows the CIO to better 'know the mind of the business' and thus to better define the priorities of the IS\&T effort. Participation in senior management strategy meetings have been found important for ensuring CIOs can bridge the gap between IS\&T and strategic business objectives (Stephens et al., 1992). At the same time, top management can play a very important role in the guidance of CIOs and improvement of the information systems function (Doll, 1985). CIO participation on the TMT can facilitate knowledge transfer (Boynton et al., 1994), coalition formation and enhance the CIO's political influence. It follows that:

\section{Hypothesis 3c: The greater the involvement of the CIO on the TMT, the greater will be the contribution of IS\&T to business performance}

Following Smaltz et al. (2006), competence is hypothesised as mediating between the CIO's organisational positioning and performance i.e. competence is considered necessary to translate the opportunities provided by structural power and political interactions into performance outcomes. Although the causal relationships are ambiguous, since competence might result in improved structural power and greater opportunities for interaction with the TMT, the empirical evidence provided by Smaltz et al. (2006) suggests that:

\section{Hypothesis 4: CIO competence mediates between CIO organisational positioning and the contribution of IS\&T to business performance}

\subsection{Control variables}

The IS field has recognised that differences exist in the information intensity of industries (McFarlan, McKenney \& Pyburn, 1983). Because IS may contribute more positively to the performance of organisations in information intensive service industries than those in manufacturing and construction, it is necessary to include industry as a control variable in the model.

Organisation size has also been related to various characteristics of computer usage among organisations (DeLone, 1981). Information systems need to help larger, more complex organisations manage their wider networks of operations and navigate through multiple domains (Yasai-Ardekani \& Haug, 1997). Thus an organisation which is fairly diverse, large in size and fairly distributed will require significantly different levels of IS support from an organisation that is small, simple and homogenous. Organisation size as reflected by the number of employees will therefore be included as a control variable in the model.

\section{4}

\section{Research methodology}

\subsection{The instrument}

A structured questionnaire was constructed to capture information from chief information officers on CIO demography, the dimensions 
of $\mathrm{CIO}$ competence, CIO organisational positioning, and IS\&T business contribution. Measurement of business knowledge and technology management knowledge drew largely from the work of Armstrong \& Sambamurthy (1999). Business knowledge was a three item, seven-point, Likert-type scale measuring perceived knowledge of the organisation's competitors; strategies, processes and products; and industry best practices. Technology management knowledge was a three item, seven-point, Likert-type scale measuring perceived knowledge of how to utilise IT to address business needs; how to identify IT for supporting the organisation's strategies and business processes; and how to guide the organisation's decisions related to the timing and level of investment in IT. Interpersonal and political competence was operationalised after Lee et al. (1995) as a four item, seven-point, Likert-type scale measuring perceived efficacy to plan and execute work in a collaborative environment; maintain productive user or client relationships; plan, organise, and lead projects; and to be self-directed and proactive. Reporting level was operationalised using a single scale item, which asked CIOs to indicate their hierarchical distance from the CEO. Degree of CIO involvement with the TMT was measured as a single scale item ranging from $1=$ never to $4=$ always involved. The frequency of CEO-CIO interaction was measured as a single scale item from $1=$ never to $6=$ daily. The questionnaire also asked for CIO age and details of level of education and degrees obtained, which were then coded from $1=$ no formal qualification to $6=$ doctoral degree. Years of IS\&T specific and total work experience were also questioned. The CIOs IS\&T experience was then measured as $1-p_{i}$ where $p_{i}$ is the proportion of total years of work experience spent in the IS\&T area - this is an adaptation of the approach used to measure the heterogeneity of CEO functional experience in Rajagopalan and Datta (1996). Given that lower scores on this measure imply a higher IS\&T specialisation, a negative relationship between this measure and IS\&T contribution is expected for the confirmation of Hypothesis 1a.

Contribution of IS\&T was operationalised as the perceived contribution of IS to organisational productivity, cost reduction, profitability, product/service differentiation, customer satisfaction, and overall business success, captured on a seven-point scale ranging from poor to excellent (Epstein \& Rejc, 2005).

Industry was measured by asking respondents to indicate their organisation's primary industry category. These were then classified into a single dichotomous variable broadly representing service (coded 1) and manufacturing/construction oriented (coded 0 ) industries. Organisation size was measured as a categorical variable of the number of employees.

\subsection{The sample}

The sampling frame for the study consisted of 421 organisations: comprising 337 organisations listed on the JSE (Johannesburg Securities Exchange) supplemented with 84 large, unlisted organisations of similar characteristics. In the case of listed holding companies, subsidiaries were targeted. All targeted companies were generally larger organisations, likely to be more advanced in terms of their IS\&T usage, and concerned with both IS\&T management practice and contribution to business performance. The head of IS/IT (highest ranking IT executive) within each organisation was the targeted respondent ${ }^{2}$. Prior to administration, the questionnaire was pretested for content validity and clarity. The pretest was followed by a pilot study involving selected IS managers. Their suggestions were incorporated into the final instrument.

\subsection{Response analysis}

One hundred and fourteen (114) responses were received, representing a 27 per cent response rate. However, after removing three cases where respondents did not fulfil the role of CIO, 111 useable responses remained. Table 1 illustrates the variety of titles used to describe the CIO role. Only a quarter of heads of IS\&T were using the term CIO. Interestingly, the hierarchical level of South African CIOs varies widely (Table 2). While approximately 40 per cent report at least 2 levels below the CEO, 38 per cent are still four or more levels below the CEO. Educational level of CIOs is described in Table 3. Results suggest 
a large variation in educational backgrounds. Well over half the CIOs have formal education (bachelors degree or above) with about 28 per cent having Masters degrees (the majority of which are MBAs). Yet, just over 30 per cent have no formal qualifications in either IT or business. Thus the role of education for attainment of the $\mathrm{CIO}$ role and for CIO role effectiveness requires greater exploration. Interestingly, 92 per cent of respondents were male, which raises questions about the career paths of female IS\&T professionals and highlights the evident gender bias among South African executives. The average age was 44 years (std. deviation $=$ 8.8 years) with an average work experience of 22 years of which an average of 15 years in IS\&T was reported. These figures are consistent with prior studies (e.g. Johnson \& Lederer, 2005).

Table 1:

Job titles

\begin{tabular}{|l|c|c|}
\hline \multicolumn{1}{|c|}{ Title } & Frequency & Percentage \\
\hline ClO & 30 & 27 \\
\hline IS manager & 6 & 5.4 \\
\hline IT manager & 22 & 19.8 \\
\hline General IS/IT manager & 12 & 10.8 \\
\hline Other & 39 & 35.1 \\
\hline Missing & 2 & 1.8 \\
\hline Total & $\mathbf{1 1 1}$ & $\mathbf{1 0 0} \%$ \\
\hline
\end{tabular}

\# Other included a range of titles such as: Director of Services, Manager of IS/IT and Communications, Executive of Resource Services, Chief Technology Officer, Chief Operations Officer and Financial Director.

Table 2:

$\mathrm{CIO}$ reporting level

\begin{tabular}{|l|c|c|}
\hline \multicolumn{1}{|c|}{ Hierarchical level relative to CEO } & Frequency & Percentage \\
\hline 0-1 level below & 21 & 18.9 \\
\hline 2 levels below & 25 & 22.5 \\
\hline 3 levels below & 20 & 18.0 \\
\hline 4 levels below & 10 & 9.0 \\
\hline$>$ 4 levels below & 32 & 28.8 \\
\hline Missing & 3 & 2.7 \\
\hline Total & $\mathbf{1 1 1}$ & $\mathbf{1 0 0} \%$ \\
\hline
\end{tabular}


Table 3:

$\mathrm{ClO}$ education

\begin{tabular}{|l|c|c|}
\hline \multicolumn{1}{|c|}{ Education } & Frequency & Percentage \\
\hline No qualification & 34 & 30.6 \\
\hline Diploma/certificate & 15 & 13.5 \\
\hline Undergraduate degree & 21 & 18.9 \\
\hline Postgraduate degree & 41 & 36.9 \\
\hline Total & $\mathbf{1 1 1}$ & $\mathbf{1 0 0} \%$ \\
\hline
\end{tabular}

The industry profile of responses is presented in Table 4. Large organisations are very well represented in the sample, with more than 50 per cent of the sample consisting of organisations with more than 1000 employees (see Table 5). Data from listed and unlisted organisations did not differ significantly with respect to any variables. Early and late respondents (used as a proxy for non-respondents) did not differ significantly on any of the variables. Moreover, the sample characteristics are fairly consistent with prior studies of IS\&T management in South Africa (Cohen, 2008). No sample bias or nonresponse bias is suspected.

Table 4:

Industry

\begin{tabular}{|l|c|c|}
\hline \multicolumn{1}{|c|}{ Industry } & Frequency & Percentage \\
\hline Manufacturing, mining and construction & 44 & 39.6 \\
\hline Services & 58 & 52.3 \\
\hline Missing & 9 & 8.1 \\
\hline Total & $\mathbf{1 1 1}$ & $\mathbf{1 0 0 \%}$ \\
\hline
\end{tabular}

Table 5:

Organisational size

\begin{tabular}{|l|c|c|}
\hline \multicolumn{1}{|c|}{ Organisational size } & Frequency & Percentage \\
\hline$<50$ & 6 & 5.4 \\
\hline $51-100$ & 5 & 4.5 \\
\hline $101-300$ & 8 & 7.2 \\
\hline $301-500$ & 9 & 8.1 \\
\hline $501-1000$ & 14 & 12.6 \\
\hline$>1000$ & 69 & 62.2 \\
\hline Total & $\mathbf{1 1 1}$ & $\mathbf{1 0 0 . 0}$ \\
\hline
\end{tabular}


5

\section{Empirical results}

\subsection{Exploratory analysis}

Prior to model testing, initial tests for validity and reliability were carried out on the multi-item competence scales. Principal components factor analysis (PCA) was carried out to assess the underlying factor structure of the competence scale items. The factor structure supported the theoretically defined dimensions of business, technology management, and interpersonal/ political competence. PCA also confirmed the unidimensionality of the dependent IS\&T contribution variable. Cronbach's alpha confirmed the reliability of the scales. Results are shown in Table 7 below.

Table 7:

Exploratory analysis of multi-item constructs

\begin{tabular}{|l|c|c|c|c|}
\hline \multicolumn{1}{|c|}{ Variable } & $\begin{array}{c}\text { No. of } \\
\text { items }\end{array}$ & $\begin{array}{c}\text { Lowest factor } \\
\text { loading }\end{array}$ & $\begin{array}{c}\text { Cronbach's } \\
\text { alpha }\end{array}$ & $\begin{array}{c}\text { Mean (std } \\
\text { deviation) }\end{array}$ \\
\hline Business competence & 3 & 0.735 & 0.741 & $5.30(0.86)$ \\
\hline Technology management competence & 3 & 0.725 & 0.790 & $5.36(0.82)$ \\
\hline Interpersonal and POLITICAL competence & 4 & 0.655 & 0.748 & $5.87(0.65)$ \\
\hline Contribution of IS\&T to business & 6 & 0.652 & 0.806 & $5.23(0.85)$ \\
\hline
\end{tabular}

Satisfied as to the reliability and validity of the competence scales, composite indices were calculated for each of business competence, technology management competence, and interpersonal/political competence as the arithmetic averages of their scale items weighted equally. These composite scores for the dimensions of competence were then used in subsequent model testing, which is described next.

\subsection{Hypothesis testing}

The partial least squares, or PLS, approach to structural equation modelling was employed to test the study's hypotheses (PLS-Graph software ver 3.00 build 1130). PLS is a second generation multivariate technique gaining increasing popularity in management and IS research as an alternative to more common maximum likelihood estimation (MLE) approaches to structural equation modelling such as LISREL (Chin, 1998; Gefen, Straub \& Boudreau, 2000). PLS has the ability to incorporate latent constructs and their observed indicators into the analysis. However, PLS does not provide model fit indices typical of MLE based approaches to SEM. Instead, $\mathrm{R}^{2}$ statistics are used to confirm the predictive power of the model. PLS can be used to overcome the problem of research data's frequent inability to meet the requirements of MLE (Fornell \& Bookstein, 1982). PLS makes no assumptions about scale of measurement and there are no distributional requirements (Fornell \& Bookstein, 1982). For a detailed discussion of the relative merits of both LISREL and PLS see Fornell \& Bookstein (1982).

In PLS, the analysis of the research model proceeds in two phases. First an analysis of the measurement model is undertaken, followed by an analysis of the structural model. The measurement model represents the relationships between the latent constructs and their indicators or measures. An advantage of PLS is that the measurement model can accommodate either formative or reflective indicators (Fornell $\&$ Bookstein, 1982). The formative mode is used when one wishes to model a construct as an explanatory combination of its indicators i.e. the construct is a function of (formed by) the manifest indicators. CIO organisational positioning is conceptualised as a function of structural power (hierarchical position), interaction with CEO, and involvement in the TMT. It is thus modelled in the formative mode. CIO competence is conceptualised as an underlying attribute of the CIO that gives 
rise to the observed indicators of business, technology management and interpersonal/ political competence, and is thus modelled in the reflective mode. The CIO's IS\&T experience, age and level of education were modelled as separate predictors. For the dependent construct, the six original scale items reflecting contribution of IS\&T to business performance were modelled in the reflective mode. Industry $(0=$ manufacturing /construction and $1=$ service) and organisation size (number of employees) were also included as control variables in the model.

The first phase of model testing confirmed that the constructs modelled in the reflective mode (CIO competence and contribution of IS\&T) demonstrated adequate internal consistency and convergent validity. The Fornell and Larcker internal consistency measures were 0.83 and 0.87 respectively, whilst average variance extracted scores were 0.62 and 0.53 respectively. For the CIO organisational positioning construct (modelled in the formative mode), and for the single item demography variables, these tests of internal consistency and convergent validity are not relevant.

Bootstrapping with 500 resamples was used to generate standard errors for calculating $\mathrm{t}$-values for determining significance levels. Figure 2 presents results of the test of the PLS measurement and structural model.

Figure 2:

PLS results $\left({ }^{* *} \mathrm{p}<0.01 ;{ }^{*} \mathrm{p}<0.05\right)$

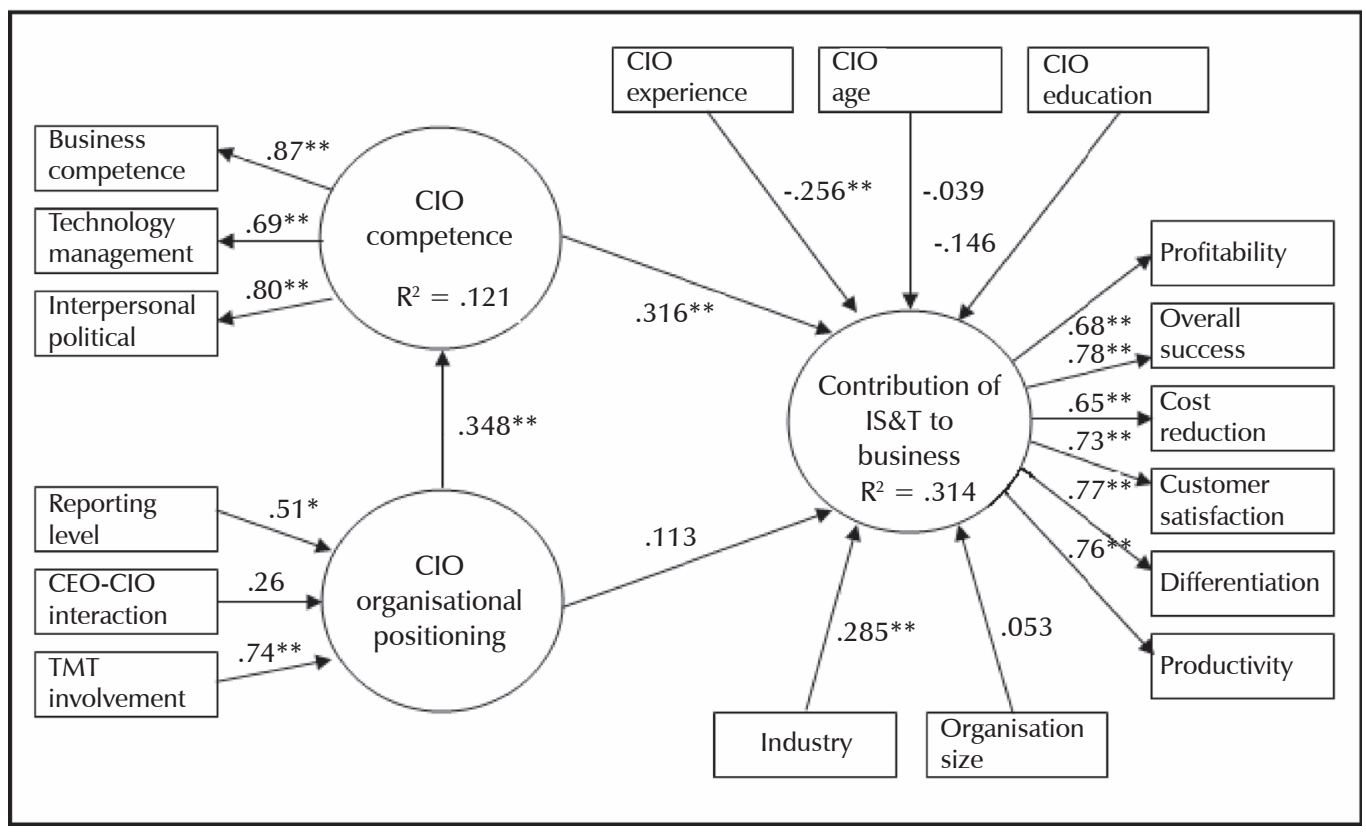

Hypothesis 1a is supported as the specialist IS\&T work experience of the CIO has a significant direct effect $(p<0.01)$ on business value of IS\&T. The negative path reflects that high IS\&T specialisation $^{3}$, leads to increased contribution of IS\&T to the business. Hypothesis $1 \mathrm{~b}$ and hypothesis $1 \mathrm{c}$ are rejected as no significant paths from age and education emerged.
Hypotheses 2a, 2b and 2c are supported. The path from CIO competence to IS\&T contribution to the business was statistically significant at the $\mathrm{p}<0.01$ level; and the significant loadings for business, technology management and interpersonal competencies confirm them as dimensions of overall competence. This strongly supports the need for South African 
CIOs to know what (business knowledge), know how (technology management knowledge), and know how to be (interpersonal and political skill) (Tagliavini et al., 2003; Lane \& Koronios, 2007).

The direct path from CIO organisational positioning to IS\&T business value was not significant and hypotheses $3 \mathrm{a}, 3 \mathrm{~b}$ and $3 \mathrm{c}$ are thus rejected. However the mediating effect of CIO competence was confirmed thus supporting hypothesis $4^{4}$. This suggests that CIO competence intervenes in the effects of both structural power and political relationship on performance. Interestingly, CEO-CIO interaction does not have a strong effect in the model. Hierarchical level and TMT involvement emerged as more important contributors to the CIO's organisational positioning.

The industry control variable had a significant effect on IS\&T business value with service sector showing greater performance. Organisation size was not found to have any significant effect.

R-squared of 0.314 indicates that the model explains about 31 per cent of the observed variance in contribution of IS\&T to business performance. Thus the predictive power of the model is confirmed.

Although not originally hypothesised or modelled, the correlations between CIO competence and CIO demography were explored. Significant correlations existed between the CIO's technology management competence and CIO experience. CIOs with a greater proportion of IS\&T specialisation in their work experience had greater technology management competence $(r=-0.229, \mathrm{p}<0.05)$. Conversely, the greater the number of years of non-IS\&T work experience of the $\mathrm{CIO}$, the poorer was the reported technology management competence $(\mathrm{r}=-0.217, \mathrm{p}<0.05)$.

A significant correlation also existed between the CIO's technology management competence and CIO education. The greater the formal education levels of the $\mathrm{CIO}$, the greater was technology management competence $(r=0.196$, $\mathrm{p}<0.05)$. CIOs with lowest levels of education had the lowest mean business $($ mean $=5.17)$ and technology management $($ mean $=5.09)$ competences, but formal education did not seem to matter as a discriminator of interpersonal skills.

\section{6 \\ Discussion}

This study aimed to address the call for increased attention to researching issues in IS\&T leadership (Karahana \& Watson, 2006). More specifically it aimed to address questions about the appropriate characteristics, competencies and skills required of CIOs, and whether the CIO's organisational position facilitated improvements in IS\&T performance. Drawing on the upper echelons perspective of Hambrick and Mason (1984), the power and politics perspective on organisations (see Pfeffer, 1992), and recent international research on CIOs, an attempt was made to examine the extent to which CIO demography (age, education and experience), CIO competence and the CIO's structural and political position affected the contribution of IS\&T to business performance.

Taken together, the results obtained in this study provide support for the upper echelons perspective that executive backgrounds, experiences and cognitions matter, yet the simpler demographic variables have less explanatory power than the upper echelons variables reflecting experience and competence.

The hypothesis that CIO education level was associated with greater IS\&T contribution was not supported. This finding is inconsistent with Li et al. (2006). They found CIO education level had a significant direct effect on organisational use of IT. The difference in findings may be due to the choice of dependent variable in this study. The effects on this study's dependent variable are most likely indirect e.g. education may indirectly impact performance through effects on the development of certain competencies. For example, this study found some connections between education and both business and technology management competence. These however require future study. Another possible explanation for the lack of significant direct effects of education is that a formal education potentially obtained many years ago may be less relevant than the more recent work experiences of the CIO (Applegate \& Elam, 1992).

Consistent with both $\mathrm{Li}$ et al. (2006) and Sobol and Klein (2009), the effects of CIO age 
could not be confirmed. A likely explanation for the finding is that age and total years of work experience highly correlate, and it is the nature and focus rather than duration of total experience that matters in the case of CIOs.

It may not be surprising, therefore, that support was found for the hypothesis that CIOs with greater IS\&T experience are associated with greater IS\&T contribution to the business. On average, South African CIOs have spent $2 / 3$ of their careers in IS\&T and the findings confirm, in part, the value of specialised as opposed to diversified functional experience in the case of South African $\mathrm{CIOs}^{5}$. The findings are consistent with Sobol and Klein's US study (2009). They suggest that appointment of a CIO with an IS\&T background may be a signal to build up IS\&T resources within the firm. As indicated by Feeny et al. (1992) such findings challenge the popular view that business managers should be transferred into senior IS\&T positions.

The study also found empirical support for the three theoretically defined dimensions of CIO competence. The findings confirm that business, technology management and interpersonal skill are important for a CIO (Romanczuk \& Pemberton, 1997; Bassellier \& Benbasat, 2004; Dawson \& Watson, 2005) and should help CIOs to meet the challenges of their role. CIOs need a solid understanding of the internal and external business domain (Armstrong \& Sambamurthy, 1999; Bassellier \& Benbasat, 2004), and of technology and how it can be used to address business needs (Armstrong \& Sambamurthy, 1999). CIOs need to develop the skills to successfully negotiate today's highly political organisational environment and to interact with business managers and lead employees (Lee et al., 1995).

It can also be inferred from the findings that CIOs that build their way up through the IS\&T ranks may still be able to develop the type of business knowledge necessary to ensure positive IS\&T contributions to the business. However, for CIOs coming from the business domain (low IS\&T specialisation) it may not be easy to develop the requisite technology management competence. Future research should build on these preliminary findings to clarify the connections between experience, education and $\mathrm{CIO}$ competence.
This study also provided some support for the power and politics view on organisations. CIO hierarchical position and TMT involvement emerged as significant contributors to CIO organisational positioning. This confirms both hierarchical position and political relationships as important sources of CIO power.

However, the CIO's position is not sufficient to provide improved IS\&T business contribution. These findings are in line with Preston et al.'s (2006) conclusion that, in both the US and French samples studied, reporting level did little to affect the level of shared understanding between the CIO and TMT on the role of IS. Hierarchical position may have been a differentiating factor when IS\&T management first emerged from the 'back room', but in today's organisational environment, CIO positioning should be considered a necessary but not sufficient condition for the delivery of IS\&T value (Smaltz et al., 2006). Moreover, the relatively weak role of CEO-CIO interaction in the CIO's organisational positioning can be understood by Hambrick's (2007) view that 'leadership of a complex organization is a shared activity, and the collective cognitions, capabilities, and interactions of the entire TMT enter into strategic behaviors', and therefore interactions between the $\mathrm{CIO}$ and the entire TMT rather than just the CEO would offer the best explanations for IS\&T outcomes.

Furthermore, despite arguments that CIOCEO/TMT interaction and engagement are crucial to ensuring that IS\&T helps shape the business and contribute to its success (Feeny et al., 1992; Reich and Benbasat, 2000), the findings reported in this study shed light on the important intervening factor of CIO competence. This is consistent with Smaltz et al.'s (2006) study of CIOs in the US healthcare sector and the earlier study of Armstrong and Sambamurthy (1999) who found CIO knowledge to be an important mediator. This may imply that structural power and partnership with the TMT merely confers the CIO with the appropriate opportunities (Smaltz et al., 2006). Unless the CIO has the interpersonal skills and business knowledge to successfully negotiate those exchanges and gain support, and unless the CIO has the technology management competence to take action, the 
contribution of IS\&T to tangible measures of business performance will not result.

Similarly, efforts on the part of the CEO and TMT to improve working relationships with the CIO may not lead to the type of performance outcomes they hope to expect unless the CIO has developed the necessary competencies. These findings are supportive of the anecdotal evidence that CIOs are held directly accountable for disappointing returns from IS\&T investment, and the high turnover rates amongst CIOs are likely to continue until the right match between CIO competence and organisational needs are found.

Future research should explore the potential impacts of managerial discretion (latitude of action) as spoken about in relation to the upper echelons theory (see Hambrick, 2007) and considered in past CIO research (Preston et al., 2008). Managerial discretion may have a moderating effect on this study's research model. When discretion of action is lacking (i.e. when one's hands are tied) then managerial characteristics (specifically competence) will have less impact on performance outcomes.

Future research may also wish to carry out a longitudinal study to account for possible time lags in the effects of CIOs on performance. Newly appointed CIOs undoubtedly need to deal with legacy environments, which are likely to significantly reduce the ability of the CIO to effect immediate performance improvements in IS\&T. Unfortunately, this study was unable to control for time lags and CIO position tenure.

Future research should also overcome the limitations of this study in regard to the use of a single key informant. Although complicating data collection, researchers should consider the use of multiple key informants (including for example the CEO) and make use of objective data where possible. Future research should also consider the possibility of recursive relationships where higher performing IS\&T functions may attract more highly educated CIOs or lead the CEO and TMT to take IS\&T more seriously.

\section{7}

\section{Conclusion}

This paper presented a study of 111 South African organisations into the performance implications of CIO competence and CIO organisational position. The effects of the CIO's organisational position on the business value of IS\&T were found to be mediated by CIO competence. CIO business, interpersonal/political and technology management competence are significant determinants of an organisation's ability to extract value from their IS\&T investments. The CIO's work experience also had significant effects. Results have important implications for organisations looking to better understand the role of the $\mathrm{CIO}$ and improve the contribution of IS\&T to performance.

\section{Endnotes}

1 A trend recognised by the 2008 UKAIS conference.

2 This strategy allowed for variation in the specific titles used by organisations to describe the CIO role. Respondents were required to confirm that they served as the senior executive responsible for management of corporate information resources (Stephens et al., 1992).

3 IS\&T experience was measured as $1-p_{i}$ where $p_{i}$ is the proportion of total years of work experience spent in the IS\&T area. Thus the more years spent in IS\&T, the lower would be the score thus leading to the negative sign on the relationship.

4 The mediating effect was confirmed by carrying out the procedure suggested by Baron and Kenny. Without the inclusion of CIO competence (the mediator), organisational positioning had a significant direct effect $(\mathrm{p}<0.05)$ on IS\&T business value, but that effect became insignificant once CIO competence was introduced into the model.

5 It should be noted that CIOs from business functional backgrounds may be more reserved in reporting the contribution of IS\&T to business value.

\section{References}

APPLEGATE, L.M. \& ELAM, J.J. 1992. New information system leaders - a changing role in a changing world. MIS Quarterly, 16(4): 469-481. ARMSTRONG, C.P. \& SAMBAMURTHY, V. 1999. Information technology assimilation in firms: the influence of senior leadership and IT infrastructures. Information Systems Research, 10(4): 304-327. ASTLEY, W.G. \& SACHDEVA, P.S. 1984. Structural sources of intraorganizational power: a theoretical synthesis. Academy of Management Review, 9(1): 104-113. 
BANKER, R., HU, N. \& PAVLOU, P.A. 2004. IT orientation, CIO reporting structure, and firm performance: to whom should the CIO report? Available online: http://opim-sun.wharton.upenn. edu/wise2004/sun112.pdf.

BASSELLIER, G. \& BENBASAT, I. 2004. Business competence of information technology professionals: conceptual development and influence on IT-business partnership. MIS Quarterly, 28(4): 673-694.

BOYNTON, A.C., ZMUD, R.W. \& JACOBS, G.C. 1994. The influence of IT management practice on IT use in large organizations. MIS Quarterly, 18(3): 299-318.

CHATTERJEE, D., RICHARDSON, V.J. \& ZMUD, R.W. 2001. Examining the shareholder wealth effects of announcements of newly created CIO positions, MIS Quarterly, 25(1): 43-70.

CHEN, D.Q. \& PRESTON, D.S. 2007. Understanding CIO role effectiveness: the antecedents and consequents. Proceedings of the 40th Hawaii International Conference on System Sciences, 3-6 January, Waikoloa, Hawaii.

CHIN, W. 1998. Issues and opinion on structural equation modeling. MIS Quarterly, 22(1): vii-xvi. CIO.COM 2009. The state of the CIO '09, CIO.com, Available online: http://assets.cio.com/documents/ cache/pdfs/2009_state_of_the_cio_charts.pdf. COGHLAN, L. \& HURLEY, M. 1996. A profile of the information technology executive, Information Management and Computer Security, 4(1): 5-13. COHEN, J.F. 2008. Contextual determinants and performance implications of information systems strategy planning within South African firms. Information \& Management, 45(8): 547-555.

DAWSON, G. \& WATSON, R. 2005. What really matters: an empirical study on the relative importance of the CIO and the maturity of the IS organization in producing effective IS performance. Proceedings of the 2005 Southern Association of Information Systems Conference, pp. 233-240.

DELOITTE UK \& CRANFIELD SCHOOL OF MANAGEMENT. 2008. Realising value from a CIO: navigating the silicon ceiling. Available online: http://www.deloitte.com/dtt/cda/doc/ content/UK_C_ RealisingValueFromACIO.pdf.

DELONE, WH 1981. Firm size and the characteristics of computer use, MIS Quarterly, 5(4): 65-77. DOLL, W.J. 1985. Avenues for top management involvement in successful MIS development. MIS Quarterly, 9(1): 17-35.

EARL, M.J. \& FEENY, D.F. 1995. Is your CIO adding value? The McKinsey Quarterly, 1995 Issue 2: 144-161. EISENHARDT, K.M. \& BOURGEOIS, L.J. 1988. Politics of strategic decision making in high-velocity environments: toward a midrange theory. Academy of Management Journal, 31(4): 737-770.

EISENHARDT, K.M. \& ZBARACKI, M.J. 1992.

Strategic decision making. Strategic Management Journal, 13(Winter): 17-37.

ENNS, H.G. 2005. Do IT professionals need business acumen to build effective partnerships. Academy of Management Executive, 19(2):159-161.

ENNS, H.G., HUFF, S.L. \& GOLDEN, B.R. 2001.

How CIOs obtain peer commitment to strategic IS proposals: barriers and facilitators. Journal of Strategic Information Systems, 10(1): 3-14.

ENNS, H.G., HUFF, S.L. \& GOLDEN, B.R. 2003.

CIO influence behaviors: the impact of technical background, Information \& Management. 40(5): 467-485. ENNS, H.G., HUFF, S.L. \& HIGGENS, C.A. 2003. CIO lateral influence behaviors: gaining peers' commitment to strategic information systems. MIS Quarterly, 27(1): 155-176.

EPSTEIN, M.J. \& REJC, A. 2005. How to measure and improve the value of IT. Strategic Finance, 87(4): 35-41.

EVANS, N. 2006. Leading information technology in South Africa: a unique challenge. Proceedings of SIGMIS-CPR'06, April 13-15, 2006, Claremont, California, USA: 90-96.

FEENY, D.F., EDWARDS, B.R. \& SIMPSON, K.M. 1992. Understanding the CEO/CIO relationship. MIS Quarterly, 16(4): 435-448.

FINKELSTEIN, S. \& HAMBRICK, D.C. 1990.

Top management team tenure and organizational outcomes: the moderating role of managerial discretion. Administrative Science Quarterly, 35(3):484503.

FORNELL, C. \& BOOKSTEIN, F.L. 1982. Two structural equation models: LISREL and PLS applied to consumer exit-voice theory. Journal of Marketing Research, 19(4): 440-452.

GARTNER. 2007. Gartner predicts 2008: CIO success factors - past practices will have little bearing on the future. Gartner Research, ID: G00153301, 14 December.

GEFEN, D., STRAUB, DW \& BOUDREAU, M. 2000. Structural equation modeling and regression: guidelines for research practice. Communications of the AIS, 4, Article 7.

GOTTSCHALK, P. \& TAYLOR, N.J. 2000. Strategic management of IS/IT functions: the role of the CIO. Proceedings of the 33rd Hawaii International Conference on System Sciences, 4-7 January, Maui, Hawaii.

GROVER, V., JEONG, S.R., KETTINGER, W.J. \& LEE, C.C. 1993. The chief information officer: a study of managerial roles. Journal of Management Information Systems, 10(2):107-130. 
HAMBRICK, D.C. 2007. Upper echelons theory: an update. Academy of Management Review, 32(2): 334-343.

HAMBRICK, D.C. \& MASON, P.A. 1984. Upper echelons: the organization as a reflection of its top managers. Academy of Management Review, 9(2): 193-206.

HOFFMANN, T. 1999. The meanings of competency. Journal of European Industrial Training, 23(6): 275-286. JAIN, R. 1997. Key constructs in successful IS implementation: South-east Asian experience source. Omega, 25(3): 267-284.

JARVENPAA, S.L. \& IVES, B. 1991. Executive involvement and participation in the management of information systems. MIS Quarterly, 15(2): 205-227. JOHNSON, A.M. \& LEDERER, A.L. 2005. The effect of communication frequency and channel richness on the convergence between chief executive and chief information officers. Journal of Management Information Systems, 22(2): 227-252.

JOHNSTON, K.; MUGANDA, N. \& THEYS, K. 2007. Key issues for CIOs in South Africa. Electronic Journal on Information Systems in Developing Countries, 30(3): 1-11.

JONES, M.C. \& ARNETT, K.P. 1994. Linkages between the CEO and the IS environment: An empirical assessment. Information Resources Management Journal, 7(1): 20-34. JONES, M.C.; TAYLOR, G.S. \& SPENCER, B.A. 1995. The CEO/CIO relationship revisited: an empirical assessment of satisfaction with IS. Information \& Management, 29(3): 123-130. KARAHANNA, E. \& WATSON, R.T. 2006. Information systems leadership. IEEE Transactions on Engineering Management, 53(2): 171-176.

KARIMI, J., GUPTA, Y.P. \& SOMERS, T.M. 1996.

The congruence between a firm's competitive strategy and information technology leader's rank and role. Journal of Management Information Systems, 13(1): 63-88. KRISHNAN, H.A. \& PARK, D. 1998. The influence of top management team leadership on corporate refocusing: a theoretical framework. Journal of Leadership Studies, 5(2): 50-61.

LANE, M.S. \& KORONIOS, A. 2007. Critical competencies required for the role of the modern CIO. Proceedings of the 18th Australasian Conference on Information Systems, 5-7 Dec 2007, Toowoomba, Australia: 1099-1109.

LEE, D.M.S., TRAUTH, E.M. \& FARWELL, D. 1995. Critical skills and knowledge requirements of IS professionals: a joint academic/industry investigation. MIS Quarterly, 19(3): 313-340.

LEE, G.G. \& PAI, J. 2003. Effects of organizational context and inter-group behaviour on the success of strategic information systems planning: an empirical study. Behaviour and Information Technology, 22(4): 263-280.

LEE, S., YEN, D., HAVELKA, D. \& KOH, S. 2001. Evolution of IS professionals' competency: an exploratory study, Journal of Computer Information Systems, 41(4): 21-31.

LI, Y., TAN, C.H., TEO, H.H. \& TAN, B.C.Y. 2006. Innovative usage of information technology in Singapore organizations: do CIO characteristics make a difference? IEEE Transactions on Engineering Management, 53(2): 177-190.

LOFGREN, C. 2003. The importance of being influential. CIO.com, Available online: http://www. cio.com/article/31781/The_Importance_of_Being_ Influential.

MCFARLAN, F.W., MCKENNEY, J.L. \& PYBURN, P. 1983. The information archipelago - plotting a course. Harvard Business Review, 61(1): 145-156. MCKENNA, S. 2004. Predispositions and context in the development of managerial skills. Journal and Management Development, 23(7): 664-677.

OVERBY, S. 2003. The incredible shrinking CIO, CIO.com, Available online: http://www.cio.com/ article/29840/The_Incredible_Shrinking_CIO. PERLMAN, E. 2007. Topside turnover. Governing. com, Available online:

http://www.governing.com/article/topside-turnover. PFEFFER, J. 1992. Managing with power: politics and influence in organizations, Boston: Harvard Business School Press.

PIGNI, F., RAVARINI, A., TAGLIAVINI, M., MORO, J. \& GUIMARAES, T. 2002. Using ICT to improve SMEs performance: does the CIO matter? Proceedings of SCI 2002 Conference, July 2002, Orlando, USA.

PRESTON, D.S., KARAHANNA, E. \& ROWE, F. 2006. Development of shared understanding between the chief information officer and top management team in U.S. and French organizations: a crosscultural comparison. IEEE Transactions on Engineering Management, 53(2): 191-206.

PRESTON, D.S., CHEN, D. \& LEIDNER, D.E. 2008. Examining the antecedents and consequences of CIO strategic decision-making authority: an empirical study. Decision Sciences, 39(4): 605-642.

RAGHUNATHAN, B. \& RAGHUNATHAN, T.S. 1989. Relationship of the rank of information systems executive to the organizational role and planning dimensions of information systems. Journal of Management Information Systems, 6(1): 111-126. RAJAGOPALAN, N. \& DATTA, D.K. 1996. CEO characteristics: does industry matter? Academy of Management Journal, 39(1): 197-215. 
RANGANATHAN, C. \& JHA, S. 2008. Do CIOs matter? Assessing the value of CIO presence in top management teams. Proceedings of the International Conference on Information Systems (ICIS), 14-17 December, Paris France.

RANGANATHAN, C. \& KANNABIRAN, G. 2004. Effective management of information systems function: an exploratory study of Indian organizations. International Journal of Information Management, 24: 247-266.

RAVARINI, A., MORO, J., TAGLIAVINI, M. \& GUIMARAES, T. 2001.Exploring the impact of CIO competence on company performance. Proceedings of Information Resources Management Association Annual Conference, 20-23 May, Toronto, Canada.

REICH, B.R. \& BENBASAT, I. 2000. Factors that influence the social dimension of alignment between business and information technology objectives. MIS Quarterly, 24(1): 81-113.

RIVARD, S., RAYMOND, L. \& VERREAULT, D. 2006. Resource-based view and competitive strategy: an integrated model of the contribution of information technology to firm performance. Journal of Strategic Information Systems, 15: 29-50.

ROEPKE, R., AGARWAL, R. \& FERRATT, R.W. 2000. Aligning the IT human resource with business vision: the leadership initiative at 3M. MIS Quarterly, 24(2): 327-353.

ROMANCZUK, J.B. \& PEMBERTON, J.M. 1997. The chief information officer: rise and fall, ARMA Records Management Quarterly, 31(2): 14-26.

SMALTZ, D., SAMBAMURTHY, V. \& AGARWAL, R. 2006. The antecedents of CIO role effectiveness in organizations: an empirical study in the healthcare sector. IEEE Transactions on Engineering Management, 53(2): 207-222.

SOBOL, M.G. \& KLEIN, G. 2009. Relation of CIO background, IT infrastructure, and economic performance. Information \& Management, 46(5): 271-278.

STEPHENS, C. \& LOUGHMAN, T. 1994. The CIO's chief concern: communication. Information \& Management, 27(2): 129-137.
STEPHENS, C.S., LEDBETTER, W.N., MITRA, A. \& FORD, F.N. 1992. Executive or functional manager? The nature of the CIOs job, MIS Quarterly, 16(4): 449-467.

TAGLIAVINI, M., MORO, J., RAVARINI, A. \& GUIMARAES, T. 2003. Shaping CIO's competencies and activities to improve company performance: an empirical study. Proceedings of the European Conference on Information Systems, Naples Italy, June 19-21.

THOMPSON, J.D. (1967) Organizations in action: social science bases of administrative theory, New York: McGraw-Hill.

WATSON, R.T., KELLY, G.G., GALLIERS, R.D. \& BRANCHEAU, J.C. 1997. Key issues in information systems management: an international perspective, Journal of Management Information Systems, 13(4): 91-115.

WIERSEMA, M.F. \& BANTEL, K.A. 1992. Top management team demography and corporate strategic change. Academy of Management Journal, 35(1): 91-121.

WILLCOXSON, L. \& CHATHAM, R. 2006. Testing the accuracy of the IT stereotype: Profiling IT managers' personality and behavioural characteristics. Information and Management, 43(6): 697-705. WU, J.H., CHEN, Y.I. \& SAMBAMURTHY, V. 2008. The impacts of BTM capability and CIO role effectiveness on firms' information technology assimilation: an empirical study. Proceedings of the International Conference on Information Systems (ICIS), 14-17 December, Paris France.

YASAI-ARDEKANI, M. \& HAUG, R.S. 1997. Contextual determinants of strategic planning processes. Journal of Management Studies, 34(5): 729-767.

YUN, S. 2007. Top manager's efficacy beliefs and organizational outcomes: an application of social cognitive theory. Seoul Journal of Business, 13(2): 139-155. 